\title{
Impacto da Mineração de Areia sobre a Química das Águas Subterrâneas, Distrito Areeiro da Piranema, Municípios de Itaguaí e Seropédica, Rio de Janeiro
}

\author{
Décio Tubbs ${ }^{1}$; Eduardo Duarte Marques ${ }^{2}$; Olga V. O. Gomes ${ }^{3} \&$ \\ Emmanoel Vieira Silva-Filho ${ }^{4}$
}

\begin{abstract}
Resumo O Distrito Areeiro de Seropédica-Itaguaí, considerado um dos maiores do Brasil, fornece aproximadamente $70 \%$ da areia para a construção civil da Região Metropolitana do Rio de Janeiro. O processo de extração de areia se dá através da retirada das camadas sedimentares superficiais, caracterizadas predominantemente por depósitos de areia, fazendo com que a superfície freática do Aquífero Piranema aflore, preenchendo as cavas resultantes. Os depósitos de areia originaram-se sob condições redutoras, associadas a ambiente deposicional de linhas de costa e mangues, o que proporcionou a formação de sulfetos. Com a exposição dos sedimentos com a lavra, ocorre oxidação dos sulfetos e aumento dos teores de $\mathrm{SO}_{4}$ na água, que podem alcançar valores superiores a $90 \mathrm{mg} . \mathrm{l}^{-1}$, o que intensifica a solubilização de minerais alumino-silicáticos e consequente aumento das concentrações de $\mathrm{Al}\left(>10 \mathrm{mg} . \mathrm{l}^{-1}\right)$ nas águas.
\end{abstract}

Palavras-chave: hidrogeoquímica, acidificação, lagoas de cava, água subterrânea.

\begin{abstract}
Impact of sand mining upon the Groundwater Chemistry, Piranema Sand Mining District, Itaguai and Seropédica region, Rio de Janeiro. The Seropédica-Itaguaí Sand Mining district supplies about $70 \%$ of sand for civil construction of Rio de Janeiro Metropolitan Region. The sand extraction process is fact by the remove of the surface sedimentary layers; make water table fills the produced hole. The sand extraction activities cause the oxidation of reduced sediments (ancient coast lines lithologies - mangrove environment), providing low $\mathrm{pH}$ values (reaching values $<4$ ) and high $\mathrm{SO}_{4}$ contents (reaching more than $90 \mathrm{mg} \mathrm{L}^{-1}$ ). The relatively high acidity of these waters, similar to ore pit lakes environment and associated acid mine drainage, contributes to accelerated weathering rate, especially the silicates minerals, which produces high concentrations of $\mathrm{Al}\left(>10 \mathrm{mg} \cdot \mathrm{L}^{-1}\right)$.
\end{abstract}

Keywords: hydrogeochemistry, acidification, sand pit lakes, groundwater.

INTRODUÇÃO O Distrito Areeiro Seropédica-Itaguaí, localizado na região da baixada de Sepetiba, entre os municípios de Seropédica e Itaguaí (Fig. 1), consiste no principal fornecedor de areia para a Região Metropolitana do Rio de Janeiro (RMRJ), contabilizando cerca de 80 minas a céu aberto. Este fator se deu graças às condições geológicas da Bacia de Sepetiba, a expansão da construção civil no estado a partir da década de 60 e sua proximidade com a cidade do Rio de Janeiro.

O Distrito Areeiro de Seropédica-Itaguaí produz anualmente cerca de $6.000 .000 \mathrm{~m}^{3}$ (aproximadamente 10.000.000 $\mathrm{t}$ de areia), mais da metade da produção do estado em 2005, gerando mais de 300 empregos, dentre eles empregados diretos, terceirizados e cooperativados (DNPM 2006, ANEPAC 2008), além de centenas de empregos indiretos constituindo atividade minerária fundamental para a construção civil da cidade do Rio de Janeiro. Por se tratar de uma bacia sedimentar quaternária, a baixada de Sepetiba possui características sedimentológicas excelentes para, além da extração de areia, o armazenamento e transmissão de água em subsuperfície (boa porosidade e permeabilidade, respectivamente). Aspectos esses que tornam a Formação Piranema (Góes 1999) um aquífero com boas características hidrogeológicas, denominado Aquífero Piranema.

Os aquíferos rasos são mais suscetíveis a impactos antropogênicos, seja através de contaminação antrópica ou por alteração do nível hidrodinâmico provocado, por exemplo, pela extração da água subterrânea que pode ocasionar alteração no regime do fluxo d'água induzindo, muitas das vezes, a recarga de água superficial e/ou de outros aquíferos adjacentes, fatores esses que contribuem para mistura das águas (Custódio \& Llamas 1983). Não obstante, sabe-se que o processo de extração de areia que é realizado na área de estudos, através da remoção de camadas sedimentares superficiais, expõe a

1 - Departamento de Geociências, Universidade Federal Rural do Rio de Janeiro, Seropédica (RJ), Brasil. E-mail: tubbs@ufrrj.br

2 - CPRM - Serviço Geológico do Brasil, Belo Horizonte (MG), Brasil. E-mail: edmarques@bh.cprm.gov.br

3 - Instituto Três Rios, Universidade Federal Rural do Rio de Janeiro, Três Rios (RJ), Brasil. E-mail: olga gomes@ufrrj.br

4 - Instituto de Química, Universidade Federal Fluminense, Niterói (RJ), Brasil. E-mail: geoemma@vm.uff.br 
superfície freática, preenchendo as cavas abertas para a retirada de areia. Os impactos gerados por essa atividade consistem na elevação do nível freático na região das cavas e comprometimento da qualidade da água associado a riscos de contaminação, por óleo combustível, das máquinas de escavação ou ainda por resíduos industriais (Berbert 2003. Marques et al. 2008), além de apresentarem águas ácidas resultantes da exposição e consequente oxidação de sedimentos redutores contendo sulfetos. A acidificação das águas que preenchem as cavas de mineração tem se tornado motivo de preocupação após o descomissionamento das minas. A exposição dos sedimentos, durante o processo de mineração de areia, na presença de água, oxida minerais de sulfeto, reduzindo o $\mathrm{pH}$ e disponibilizando contaminantes tóxicos a biota aquática (Lopes et al. 1999, McCullough \& Lund 2006, Modis et al. 1998, Bachmann et al. 2001, Ramstedt et al. 2003, Denimal et al. 2005, Pellicori et al. 2005, Sheoran and Sheoran 2006, Neil et al. 2009).
O objetivo deste estudo é avaliar o impacto da atividade de extração de areia sobre a qualidade das águas subterrâneas, através da caracterização hidrogeoquímica das águas nas cavas de extração de areia, bem como nos poços de produção de água na região dos areais.

CARACTERÍSTICAS DA ÁREA ESTUDADA A Bacia Sedimentar de Sepetiba ocupa uma área correspondente a cerca de 4\% da área do Estado do Rio de Janeiro, estando delimitada pela linha cumeada da Serra do Mar, onde nascem os rios que deságuam na Baía de Sepetiba e formadores da bacia hidrográfica do Rio Guandu, a saber, rios da Guarda e Guandu-Mirim (SEMA 1996). Esta bacia ocupa uma área de cerca de $2.000 \mathrm{~km}^{2}$, sendo que $70 \%$ de sua área total correspondem a uma planície aluvionar (Fig. 1), onde se localizam os municípios de Seropédica e Itaguaí, região do estudo, inserida entre as coordenadas UTM horizontais



Figura 1 - Limites do aquifero Piranema e localização da área de estudo. Na parte inferior da ilustração, grande número de cavas de extração de areia, ao longo da área, e os areais estudados, em negrito. 
(7.470.000 e 7.478.000 Norte) e verticais $(630.000$ e 638.000 Leste).

O Rio Guandu é o principal fornecedor de água para o abastecimento da Região Metropolitana do Rio de Janeiro (RMRJ), teve sua vazão aumentada para 160 $\mathrm{m}^{3} \mathrm{~s}^{-1}$ na década de 1950 , através da transposição das águas dos rios Ribeirão das Lages, Piraí e Paraíba do Sul, para inicialmente gerar energia e posteriormente suprir a crescente demanda de água na Região Metropolitana da Cidade do Rio de Janeiro. As águas deste rio são captadas e tratadas pela maior estação de tratamento de água da América Latina, a Estação de Tratamento (ETA) do Guandu, e distribuídas para aproximadamente 8,5 milhões de pessoas (Rios \& Berger 2002). Depois da estação de tratamento do Guandu esse rio recebe as águas do rio Guandu-Mirim e é dividido em vários canais no bairro de Santa Cruz, no Rio de Janeiro, sendo o principal deles o Canal de São Francisco que serve à Zona Industrial de Santa Cruz desaguando finalmente na Baía de Sepetiba.

Devido a sua posição litorânea, a topografia exerce uma forte influência na delimitação de áreas mais chuvosas e menos chuvosas na área de estudo. Os ventos são do quadrante Sul, de onde são provenientes os principais sistemas produtores de chuva na região, ou seja, os sistemas frontais (Nimer 1977). Essa região possui clima úmido, com temperaturas médias elevadas (acima de $18^{\circ} \mathrm{C}$ ) o ano inteiro e precipitação média anual em torno de $1.725 \mathrm{~mm}$. As chuvas são distribuídas em dois períodos bem marcados, com menores intensidades registradas entre abril e outubro e as maiores entre novembro e março (SEMA 1996).

A geologia local é formada por depósitos sedimentares quaternários de ambiente aluvionar (fluvial, flúvio-marinho e flúvio-lacustre), sobrepostos ao arcabouço pré-cambriano. Os sedimentos integram a Formação Piranema (Góes 1994), sendo representados por duas unidades. A inferior apresenta fácies arenosa pleistocênica, constituída por areias de granulometria média a muito grossa com cascalho, geralmente basal. A unidade superior, denominada aluvionar é formada por fácies síltico-argilosa holocênica.

Identificações mineralógicas de amostras de sondagem (Berbert 2003) demonstraram a presença de $82,09 \%$ de quartzo e $14,22 \%$ de feldspatos $(80 \%$ de K-feldspatos e $20 \%$ de plagioclásio) e $1,65 \%$ para minerais micáceos e fragmentos de rocha, classificando, então, a fração areia como subarcoseana. Segundo Marques (2010), a história geológica da Bacia de Sepetiba remonta um antigo ambiente de linhas de costa referentes a manguezais e pântanos, o que condiciona à formação de ambiente redutor, permitindo, assim, o acúmulo de matéria orgânica e neoformação de sulfetos (pirita neoformada e gás sulfídrico).

A região da bacia de Sepetiba possui dois sistemas aquíferos: o sistema aquífero cristalino e o sistema aquífero sedimentar. O sistema aquífero cristalino é composto por rochas do Complexo Paraíba do Sul, Complexo Rio Negro, Suíte Serra das Araras, Unidade Duas Barras e Suíte Rio de Janeiro (gnaisses bandados, milonitos e migmatitos), com idades arqueanas e intensas estruturas de direção NE-SW além de corpos graníticos intrusivos, diques e brechas do Cretáceo Superior. De acordo com Eletrobolt (2003), o sistema fraturado ocorre tanto onde as rochas cristalinas afloram, quanto nas regiões de baixada, onde está encoberto pelos sedimentos quaternários ou por espessas camadas de rochas alteradas geradas pelo intemperismo. $\mathrm{O}$ sistema aquífero fraturado é livre a semiconfinado, com a permeabilidade associada principalmente a fraturamentos abertos nas rochas cristalinas, possuí espessura variada, e as direções principais para o acúmulo de água são NE-SW e NW-SE.

O sistema aquífero sedimentar é formado por colúvios, depósitos fluviais, flúvio-marinhos e flúviolacustres de idades quaternária. A faciologia deste sistema consiste em cascalhos, areias e siltes inconsolidados, caracterizado como Sistema Aquífero Piranema. As sondagens realizadas na região indicam que a espessura sedimentar varia entre 16 e $40 \mathrm{~m}$. Estudos geofísicos realizados na Bacia de Sepetiba registraram profundidades do embasamento entre 50 a $60 \mathrm{~m}$ para a área da Piranema, e com informações de que os sedimentos da Formação Piranema podem atingir até $75 \mathrm{~m}$ de profundidade (Eletrobolt 2003). Observações preliminares sugerem níveis aquíferos múltiplos ou superpostos, constituindo o Aquífero Piranema, geralmente de ocorrência livre, localmente confinado, constituído por matriz grosseira arcoseana, separados em parte por lentes de argila de espessura variável.

A profundidade do nível da água subterrânea varia entre poucos centímetros a 7,5 $\mathrm{m}$, com média de 2,5 m, conforme a estação climática (Tubbs 1999). Estes aquíferos são representados pelas camadas superficiais da bacia, que por sua vez são caracterizadas por pacotes arenosos com espessuras médias em torno de 3,0 m, não apresentando padrões constantes e tampouco grandes continuidades laterais (Berbert 2003). Além dos depósitos sedimentares, as coberturas do solo oriundas das alterações das rochas cristalinas podem gerar um sistema com características superficiais de aquífero poroso e gradualmente, à medida que a profundidade aumenta, revertendo para características de sistemas fraturados (Eletrobolt 2003).

O processo de extração de areia, por dragagem se dá através da retirada das camadas sedimentares superficiais da região, caracterizadas por depósitos de areia, fazendo com que a superfície freática do Aquífero Piranema aflore, preenchendo as cavas resultantes. $\mathrm{O}$ afloramento da superfície freática, de certa forma, contribui para a maior facilidade da retirada da areia das cavas produzidas, pois auxilia no desmonte dos depósitos de areia, dependendo somente da draga para a extração. Essas cavas, entretanto possuem bordas instáveis pela falta de sustentação em sua base provocada pelo processo de dragagem. Logo, através da extração lateral de areia, as cavas atingem maiores extensões. Com a retirada dos sedimentos, o lençol freático aflora formando as lagoas (Marques 2010). Na região, essas lagoas têm uma área total de $40 \mathrm{~km}^{2}$ (Fig. 1), com profundidade de 
cerca de $28 \mathrm{~m}$ e um volume total de $540 \mathrm{~km}^{3}$ de água, totalizando mais de 300 hectares de área exposta sujeita a evaporação.

MATERIAL E MÉTODOS Para se diagnosticar a influência da exposição da água subterrânea, com a abertura das cavas com a extração de areia, foram realizadas coletas de amostras de água entre novembro de 2005 e março de 2007, em quatro cavas alagadas (Fig. 2) e em quatro poços tubulares rasos (entre 12 e $15 \mathrm{~m}$ de profundidade), adjacentes às lagoas. Três lagoas de cavas estavam em operação contínua e uma quarta operando intermitentemente. Por outro lado os poços utilizados para amostragem das águas subterrâneas eram utilizados regularmente. A periodicidade das amostragens foi mensal para as lagoas (dez campanhas) e bimensal para os poços (seis campanhas), totalizando 64 amostras. Os procedimentos de amostragem de campo seguiram orientação de Cunha \& Machado (2003).

Para a amostragem da água subterrânea, as bombas dos poços foram postas em funcionamento por aproximadamente $10 \mathrm{~min}$, tempo suficiente para extrair mais de três vezes o volume do poço, seguindo-se, então, a coleta de cada amostra. A amostragem de água das cavas alagadas foi efetuada a profundidade média de $5 \mathrm{~m}$ utilizando uma garrafa Van Dorn de 2 L. Em cada campanha de amostragem, foram medidas, no próprio local da coleta, o $\mathrm{pH}$, condutividade elétrica e temperatura, utilizando equipamento da marca Cole Palmer, e o Eh com equipamento Oakton. Em todas as campanhas, a coleta das amostras foi realizada sempre em um único dia. As amostras foram filtradas em filtro de $0,45 \mu \mathrm{m}$, acoplado a uma seringa, e divididas em duas alíquotas (cátions e ânions) e colocadas em tubo tipo falcon de $50 \mathrm{ml}$. Uma das alíquotas foi acidificada com $1 \mathrm{ml}$ de ácido nítrico concentrado para análise de metais e uma terceira alíquota de $500 \mathrm{ml}$, coletada para análise de parâmetros complementares. Após a amostragem, os recipientes foram mantidos sob refrigeração até a análise.

As análises de cátions $(\mathrm{Ca}, \mathrm{K}, \mathrm{Na}, \mathrm{Mg}, \mathrm{Al}, \mathrm{Mn}$ e $\mathrm{Fe})$ foram realizadas por ICP-OES e os ânions $(\mathrm{Cl}$, $\mathrm{SO}_{4}$ e $\mathrm{NO}_{3}$ ) por cromatografia de íons. As determinações de sílica foram realizadas por espectrometria de absorção molecular e as de alcalinidade $\left(\mathrm{HCO}_{3}\right)$ por titulação com ácido sulfúrico. Em parte do trabalho, a alcalinidade foi determinada no próprio local de amostragem. Como não foi observada qualquer diferença, a
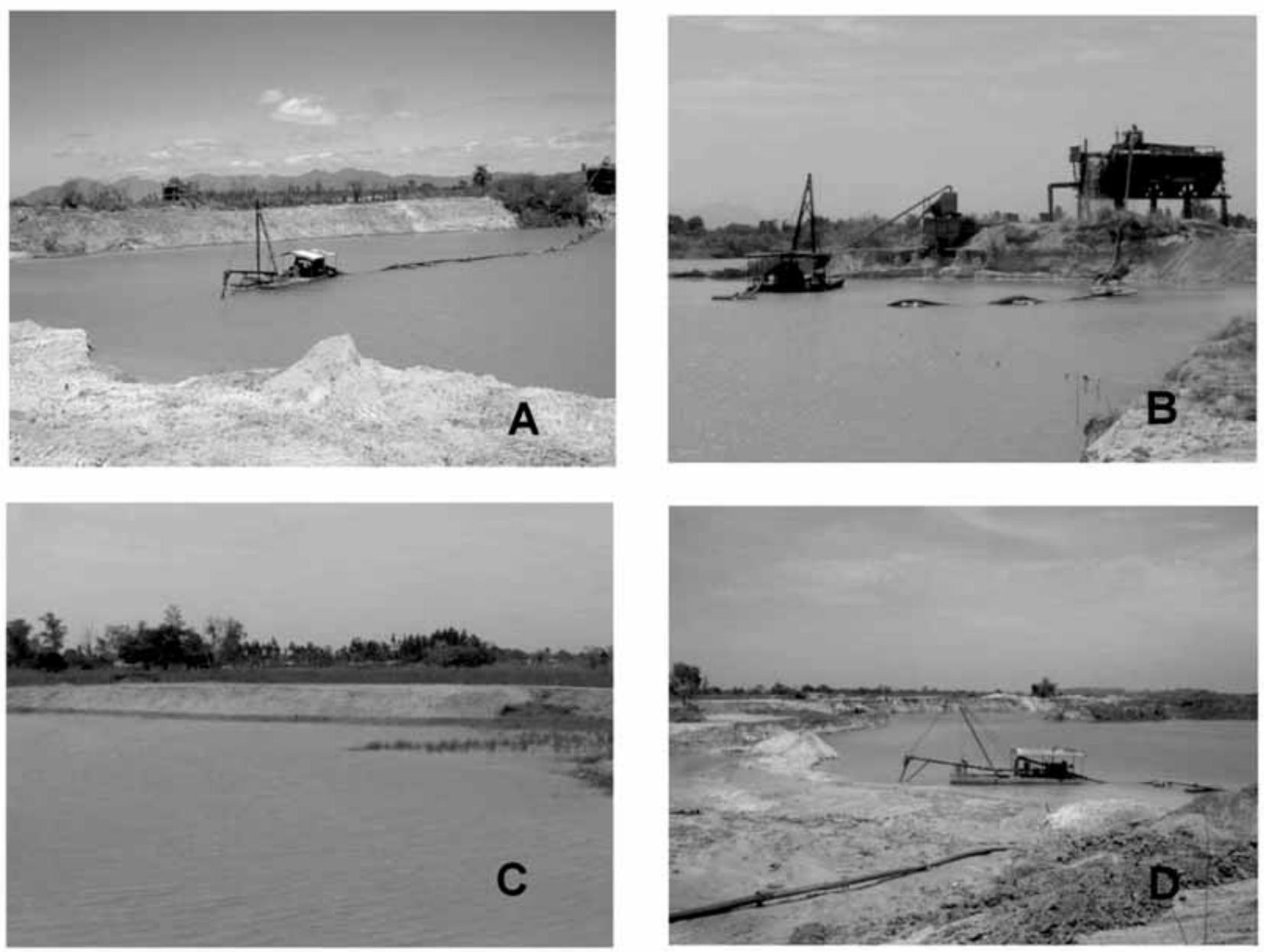

Figura 2 - Areais amostrados: Areal Fernandes e Cardoso (A); Areal Irmãos Unidos (B); Areal Santa Helena (C) e Areal LBF (D). 
partir de então, todas as determinações foram feitas no laboratório.

RESULTADOS A tabela 1 resume os resultados obtidos para os dois conjuntos de amostras, águas subterrâneas e águas das lagoas de cavas de extração, o que possibilita comparar os resultados obtidos e avaliar as alterações entre o sistema subterrâneo que alimenta as cavas. Dentre os parâmetros avaliados, pH, Eh, bicarbonato e sulfato foram aqueles que melhor expressaram as variações das concentrações entre poços e lagoas. Os valores de $\mathrm{pH}$ das águas das lagoas formadas pelas cavas são sempre ácidos e inferiores aos dos poços, nos quais se constatou $\mathrm{pH}$ de até 3,1 .

O Eh das águas das lagoas variou entre 240 e 287 $\mathrm{mV}$, valores característicos de ambientes oxidantes. Por outro lado, os Poços 03 e 04 com médias em torno de $-38 \mathrm{mV}$ e $-70 \mathrm{mV}$, respectivamente, apresentaram comportamento redutor. A média das concentrações de bicarbonato nos poços é consideravelmente superior aos observados nas lagoas. Por diversas vezes não foi detectada presença de bicarbonato nas águas das lagoas como, por exemplo, na Lagoa 01.

O ânion sulfato também mostrou diferenças de concentração significativas entre poços e lagoas. Os

Tabela 1 - Valores médios, máximos e mínimos dos principais compostos presentes nas águas (mg. $\left.L^{-1}\right), p H, C E$ (condutividade elétrica), em 24 amostras de poços e 40 amostras em lagoas de cavas.

\begin{tabular}{|c|c|c|c|c|c|c|c|c|c|c|c|c|c|c|c|}
\hline & $\mathrm{pH}$ & $\mathrm{Eh}$ & $\mathrm{CE}\left(\mu \mathrm{S} . \mathrm{cm}^{-1}\right)$ & $\mathrm{Na}$ & $\mathrm{Mg}$ & $\mathrm{K}$ & $\mathrm{Ca}$ & $\mathrm{Mn}$ & $\mathrm{Fe}$ & $\mathrm{Al}$ & $\mathrm{Cl}$ & $\mathrm{SO}_{4}$ & $\mathrm{NO}_{3}$ & $\mathrm{HCO}_{3}$ & $\mathrm{SiO}_{2}$ \\
\hline \multicolumn{16}{|l|}{ Lagoa 1} \\
\hline Média & 3,7 & 280 & 289 & 26,6 & 4,31 & 3,05 & 8,51 & 0,40 & 0,28 & 2,7 & 29,0 & 60,7 & 3,8 & $<1,0$ & 23,3 \\
\hline Máximo & 4,2 & 367 & 329 & 35,2 & 6,06 & 4,13 & 21,0 & 0,61 & 0,62 & 14,7 & 48,5 & 72,5 & 18,3 & $<1,0$ & 34,4 \\
\hline Mínimo & 3,1 & 133 & 208 & 14,6 & 1,85 & 1,50 & 4,35 & 0,06 & 0,04 & 0,06 & 5,8 & 25,7 & $<0,2$ & $<1,0$ & 2,1 \\
\hline \multicolumn{16}{|l|}{ Poço 1} \\
\hline Média & 5,4 & 124 & 216 & 24,7 & 5,91 & 3,30 & 6,63 & 0,12 & 1,07 & 1,97 & 26,9 & 37,6 & 7,3 & 15,1 & 27,45 \\
\hline Máximo & 5,8 & 195 & 234 & 28,5 & 8,91 & 4,42 & 9,93 & 0,17 & 3,60 & 7,40 & 39,6 & 72,1 & 9,2 & 17,4 & 35,7 \\
\hline Mínimo & 5,0 & $-0,2$ & 183 & 21,5 & 3,90 & 2,80 & 3,97 & 0,08 & 0,02 & 0,01 & 20,4 & 22,7 & 3,9 & 12,4 & 16,9 \\
\hline \multicolumn{16}{|l|}{ Lagoa 2} \\
\hline Média & 4,3 & 272 & 193 & 26,7 & 2,26 & 2,87 & 3,54 & 0,14 & 0,15 & 2,83 & 29,7 & 32,6 & 2,5 & 4,1 & 27,3 \\
\hline Máximo & 5,2 & 313 & 221 & 33,4 & 3,27 & 3,85 & 4,56 & 0,18 & 0,42 & 13,7 & 50,2 & 64,1 & 14,0 & 16,8 & 36,2 \\
\hline Mínimo & 3,9 & 232 & 121 & 17,7 & 1,28 & 2,19 & 2,26 & 0,10 & 0,01 & 0,01 & 17,7 & 20,6 & $<0,02$ & $<1,0$ & 13,4 \\
\hline \multicolumn{16}{|l|}{ Poço 2} \\
\hline Média & 5,0 & 161 & 185 & 27,4 & 1,21 & 2,01 & 1,85 & 0,24 & 1,03 & 2,31 & 40,8 & 5,5 & 2,1 & 11,9 & 30,0 \\
\hline Máximo & 5,4 & 262 & 262 & 35,5 & 1,90 & 2,71 & 3,08 & 0,87 & 3,54 & 9,51 & 65,4 & 13,9 & 11,2 & 17,9 & 37,3 \\
\hline Mínimo & 4,6 & 84 & 123 & 20,1 & 0,18 & 1,59 & 1,34 & 0,08 & 0,02 & 0,01 & 23,2 & 0,53 & 0,02 & 8,1 & 20,9 \\
\hline \multicolumn{16}{|l|}{ Lagoa 3} \\
\hline Média & 4,5 & 287 & 127 & 17,7 & 0,77 & 2,16 & 2,09 & 0,13 & 0,27 & 3,93 & 25,8 & 3,8 & 0,92 & 6,2 & 21,3 \\
\hline Máximo & 5,0 & 353 & 139 & 22,9 & 1,10 & 2,72 & 10,9 & 0,18 & 1,26 & 20,1 & 29,5 & 10,3 & 4,50 & 17,9 & 31,3 \\
\hline Mínimo & 3,9 & 214 & 111 & 2,72 & 0,42 & 1,82 & 0,41 & 0,06 & $<0,01$ & 0,01 & 18,6 & 0,39 & $<0,02$ & $<1,0$ & 8,8 \\
\hline \multicolumn{16}{|l|}{ Poço 3} \\
\hline Média & 5,7 & -38 & 201 & 24,1 & 1,36 & 2,60 & 2,21 & 0,57 & 17,6 & 2,80 & 28,5 & 8,6 & 2,5 & 23,9 & 27,5 \\
\hline Máximo & 6,1 & -15 & 250 & 27,8 & 4,40 & 3,62 & 6,40 & 0,95 & 34,9 & 11,6 & 39,0 & 20,7 & 14,1 & 56,0 & 36,8 \\
\hline Mínimo & 5,3 & -83 & 154 & 19,2 & 0,55 & 1,50 & 1,13 & 0,30 & 0,30 & $<0,01$ & 23,0 & 3,8 & 0,02 & 12,9 & 20,0 \\
\hline \multicolumn{16}{|l|}{ Lagoa 4} \\
\hline Média & 4,4 & 240 & 292 & 30,3 & 5,85 & 3,88 & 8,37 & 0,44 & 0,36 & 3,87 & 39,7 & 58,0 & 0,31 & 3,36 & 25,7 \\
\hline Máximo & 5,1 & 290 & 388 & 43,6 & 8,88 & 4,92 & 11,5 & 0,76 & 1,05 & 14,4 & 78,9 & 88,1 & 0,79 & 14,6 & 34,1 \\
\hline Mínimo & 3,8 & 210 & 207 & 4,79 & 3,40 & 1,52 & 4,60 & 0,21 & 0,02 & 0,04 & 16,9 & 34,6 & 0,07 & $<1,0$ & 6,8 \\
\hline \multicolumn{16}{|l|}{ Poço 4} \\
\hline Média & 5,7 & -70 & 245 & 27,6 & 3,30 & 2,98 & 5,57 & 0,37 & 11,8 & 4,12 & 28,8 & 14,1 & 0,15 & 37,3 & 26,3 \\
\hline Máximo & 6,6 & -43 & 269 & 35,0 & 4,88 & 3,57 & 9,28 & 0,48 & 18,4 & 12,3 & 34,9 & 17,7 & 0,50 & 66,1 & 32,5 \\
\hline Mínimo & 4,9 & -96 & 213 & 18,4 & 0,68 & 2,24 & 0,86 & 0,30 & 0,38 & $<0,01$ & 23,3 & 3,4 & 0,02 & 15,7 & 18,8 \\
\hline
\end{tabular}


resultados observados refletem nítido aumento das concentrações médias das águas das lagoas em relação às águas obtidas nos poços. Concentrações elevadas de sulfato nas lagoas (98 mg. $\mathrm{L}^{-1}$ ) (Marques et al. 2008); e até mesmo concentrações atingindo valores de 266 mg.L $L^{-1}$ (Terrabyte 2000), também foram constatadas, enquanto a concentração média de sulfato nos poços na região, fora da área de influência direta da mineração, é de 5,7 mg.L $\mathrm{L}^{-1}$ (Barbosa 2005).

Os valores de condutividade elétrica não apresentaram diferenças significativas entre as águas das lagoas das cavas e poços, com valores para as águas das lagoas entre 127 e $292 \mu \mathrm{S} . \mathrm{cm}^{-1}$, apresentando valores médios ligeiramente mais elevados do que valores encontrados nos poços $\left(185\right.$ e $245 \mu{\mathrm{S} . \mathrm{cm}^{-1}}^{-1}$. Os teores de $\mathrm{Cl}$ apresentaram distribuição homogênea sem grandes diferenças entre as águas dos dois sistemas.

Os teores de $\mathrm{Na}, \mathrm{K}, \mathrm{Ca}$ e $\mathrm{Mg}$ apresentaram a mesma faixa de concentração tanto nas lagoas quanto nos poços, sendo os de Na mais elevados (30,3 mg. $\mathrm{L}^{-1}$ para a lagoa 4 e 27,7 mg. $\mathrm{L}^{-1}$ para o poço 2 ) comparados aos de $\mathrm{K}, \mathrm{Ca}$ e $\mathrm{Mg}$.

A ocorrência do nitrato foi observada apenas no poço 1 , com a concentração máxima de $9,18 \mathrm{mg} . \mathrm{L}^{-1}$, e nas águas das lagoas nas últimas campanhas, mas em concentrações bem reduzidas. A ocorrência de Al, $\mathrm{Fe}$ e $\mathrm{Mn}$ nos poços e lagoas, apresentou relativamente largas faixas de variação em suas concentrações. Em certas amostras os resultados obtidos apresentaram comportamento aleatório em relação à campanha e ao local amostrado, sem, portanto, evidenciar um padrão definido. A ocorrência de outros cátions limitou-se a pequenas concentrações de $\mathrm{Zn}$ e, não sendo observada a ocorrência de outros metais em concentrações significativas, quer em poços ou lagoas.

A exceção de dois resultados com valores muito abaixo da média, a ocorrência da $\mathrm{SiO}_{2}$ apresentou comportamento uniforme sem grandes diferenças entre poços e lagoas.

DISCUSSÃO Considerando que as águas das lagoas de cavas e poços possuem a mesma origem, ou seja, são águas subterrâneas, ambas deveriam apresentar, teoricamente, a mesma composição química e mesmo comportamento ao longo do tempo. Todavia, uma análise comparativa de determinados parâmetros entre os dois grupos de amostras resultou na constatação de diferenças composicionais entre as mesmas.

As águas das lagoas de cava possuem características peculiares se comparadas a águas naturais superficiais e subterrâneas, principalmente ao se levar em conta os valores de sulfato, $\mathrm{pH}$ e alumínio. Guardadas as devidas proporções tais valores são comparados a lagoas ácidas de minas em minerações de minérios sulfetados. Estes ambientes são característicos por possuírem altos teores de metais pesados dissolvidos em suas águas devido ao baixo $\mathrm{pH}$, além de altos teores de sulfato (Alpers \& Blowes 1994, Jambor \& Blowes 1994, Plumlee \& Logsdon 1999, Schultze et al. 2010).
Contudo, apesar da região não possuir qualquer mineralização desta natureza, a resposta para a acidificação das águas das cavas de extração de areia está diretamente ligada à geologia da bacia, mais intrinsecamente na composição mineralógica dos sedimentos. A história geológica da Bacia de Sepetiba remonta um antigo ambiente de linhas de costa, manguezais e pântanos, o que condiciona a formação de um ambiente redutor, permitindo, assim, o acúmulo de matéria orgânica e neoformação de sulfetos (pirita neoformada e gás sulfídrico). Ao atingir camadas com tais características, as dragas de sucção desencadeiam o processo de oxidação do material reduzido, que, por sua vez, condicionam a formação de ácido sulfúrico $\left(\mathrm{H}_{2} \mathrm{SO}_{4}\right)$, que, por ser um ácido forte, se dissocia rapidamente em íons $\mathrm{H}^{+} \mathrm{e} \mathrm{SO}_{4}{ }^{2-}$ (equações 1 e 2).

$$
\begin{aligned}
& 2 \mathrm{FeS}_{2(\mathrm{~s})}+2 \mathrm{H}_{2} \mathrm{O}_{(\mathrm{l})}+7 \mathrm{O}_{2(\mathrm{~g})} \leftrightarrow 2 \mathrm{H}_{2} \mathrm{SO}_{4(\mathrm{aq})}+2 \mathrm{FeSO}_{4(\mathrm{~s})} \\
& 2 \mathrm{H}_{2} \mathrm{SO}_{4(\mathrm{aq})} \leftrightarrow 4 \mathrm{H}^{+}+2 \mathrm{SO}_{4}{ }^{2-}
\end{aligned}
$$

A concentração de íons $\mathrm{H}^{+}$faz com que o alumínio, presente nas argilas e mineral silicáticos (tais como micas), seja dissolvido na água (Marques et al. 2008, 2010).

Este fato pode ser mais bem evidenciado com a utilização do diagrama de Piper (Fig. 3). Nota-se, então, a diferença composicional bem estabelecida entre as águas dos poços e lagoas, embora ambas tenham uma única origem, permitindo comprovar a existência de uma evolução hidrogeoquímica, experimentada pelas águas subterrâneas devido à exposição do nível freático nas lagoas de extração de areia. Portanto, as águas derivadas dos poços podem ser classificadas como cloretada-bicarbonatada-sódica e cloretada-sulfatada-sódica, Por outro lado, as águas das cavas são classificadas como cloretada-sulfatada-sódica ou



Ca

$\mathrm{Na} \mathrm{HCO}_{3}$

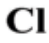

\section{Lagoas de Cava}

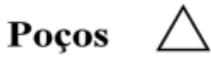

Figura 3 - Diagrama de Piper para as amostras das águas das lagoas de cava e dos poços. 
sulfatada-cloretada-sódica, muito próximas ao campo das águas sulfatadas sódicas.

Neste sentido, fica evidente que a atividade de extração de areia é responsável pelas mudanças físico-químicas da água subterrânea aflorante nas cavas. Os parâmetros físico-químicos que representam estas mudanças são o pH, Eh e a condutividade elétrica (CE) e estes, por sua vez, controlam a disponibilidade dos demais componentes presentes na água. A Condutividade Elétrica, tanto das lagoas de cava quanto das águas subterrâneas, possuem relativamente baixos valores (Bidone et al. 1999) e isso pode se dever à mineralogia predominante da Bacia Sedimentar de Sepetiba, essencialmente quartzo-feldspática, matriz de difícil dissolução. Por outro lado, os baixos valores de $\mathrm{pH}$ provavelmente são devidos a oxidação de compostos reduzidos do sedimento durante o processo de extração da areia.

A figura 4 mostra o gráfico de $\mathrm{CE}$ em função do $\mathrm{pH}$ para as amostras das lagoas de cava e dos poços amostrados. Ao contrario do que se observa nos poços, os maiores valores de CE (que representam os componentes dissolvidos na água) se associam aos menores valores de $\mathrm{pH}$ para amostras das lagoas. Isto evidencia claramente as mudanças físico-químicas que ocorrem neste ambiente com a abertura das cavas.

As figuras 5, 6 e 7 ilustram o comportamento dos componentes das águas das lagoas e dos poços em função dos parâmetros físico-químicos $\mathrm{CE}$ e $\mathrm{pH}$. Os cátions maiores $\mathrm{Na}, \mathrm{Mg}$ e Ca, além do $\mathrm{SO}_{4}$ e $\mathrm{Mn}$, apresentam correlações significativas com a condutividade elétrica para as lagoas. O íon K, apesar de indicar certa tendência em relação a $\mathrm{CE}$ nas lagoas, não possui valor significativo de correlação. Os demais componentes ( $\mathrm{Fe}, \mathrm{Al}, \mathrm{SiO}_{2}, \mathrm{Cl}, \mathrm{NO}_{3}$ e $\mathrm{HCO}_{3}$ ) não mostram qualquer tendência e tampouco correlação significativa com a $\mathrm{CE}$, sugerindo diferentes características entre as lagoas (p.ex. litologia), e provavelmente devido a fatores externos, tal como a pluviosidade e estágio de desenvolvimento das cavas (Marques et al. 2010). Para os poços, onde ocorre faixa de valores de $\mathrm{CE}$ menor em relação às lagoas (entre 123 e $269 \mu \mathrm{S} . \mathrm{cm}^{-1}$ ), os componentes analisados não apresentam correlações significativas com este parâmetro.

Em relação ao $\mathrm{pH}$, os íons $\mathrm{Na}, \mathrm{Mg}, \mathrm{K}, \mathrm{Ca}, \mathrm{Al}$ e $\mathrm{SO}_{4}$ apresentam comportamentos nos gráficos semelhantes à figura 4 , com valores maiores para as lagoas (menores valores de $\mathrm{pH}$ ) do que para os poços (maiores valores de $\mathrm{pH}$ ), corroborado pelas significativas correlações destes com a CE. Os íons $\mathrm{Mn}$ e $\mathrm{Fe}$ apresentam comportamento antagônico aos supracitados, com maiores valores para os poços e menores para as lagoas, fato que mostra a influência das variações do Eh antes e depois da abertura das cavas. Enquanto em ambiente mais redutor (poços), o $\mathrm{Mn}$ e Fe na forma reduzida $\left(\mathrm{Mn}^{2+} \mathrm{e} \mathrm{Fe}^{2+}\right.$ respectivamente) teriam maior probabilidade de dissolução no meio aquoso, logo, maiores valores. Por outro lado, em ambiente oxidante (lagoas), estes mesmos poderiam precipitar como hidróxidos, no caso do $\mathrm{Fe}$, e co-precipitar com hidróxidos de ferro e adsorver em sítios de troca catiônica, no caso do $\mathrm{Mn}$ (argilas, matéria orgânica e fases coloidais), sendo, portanto, então, retirados do meio aquoso.

$\mathrm{A} \mathrm{SiO}_{2}$ apresenta valores equiparados tanto nas lagoas (baixo $\mathrm{pH}$ ) quanto nos poços ( $\mathrm{pH}$ mais elevado),

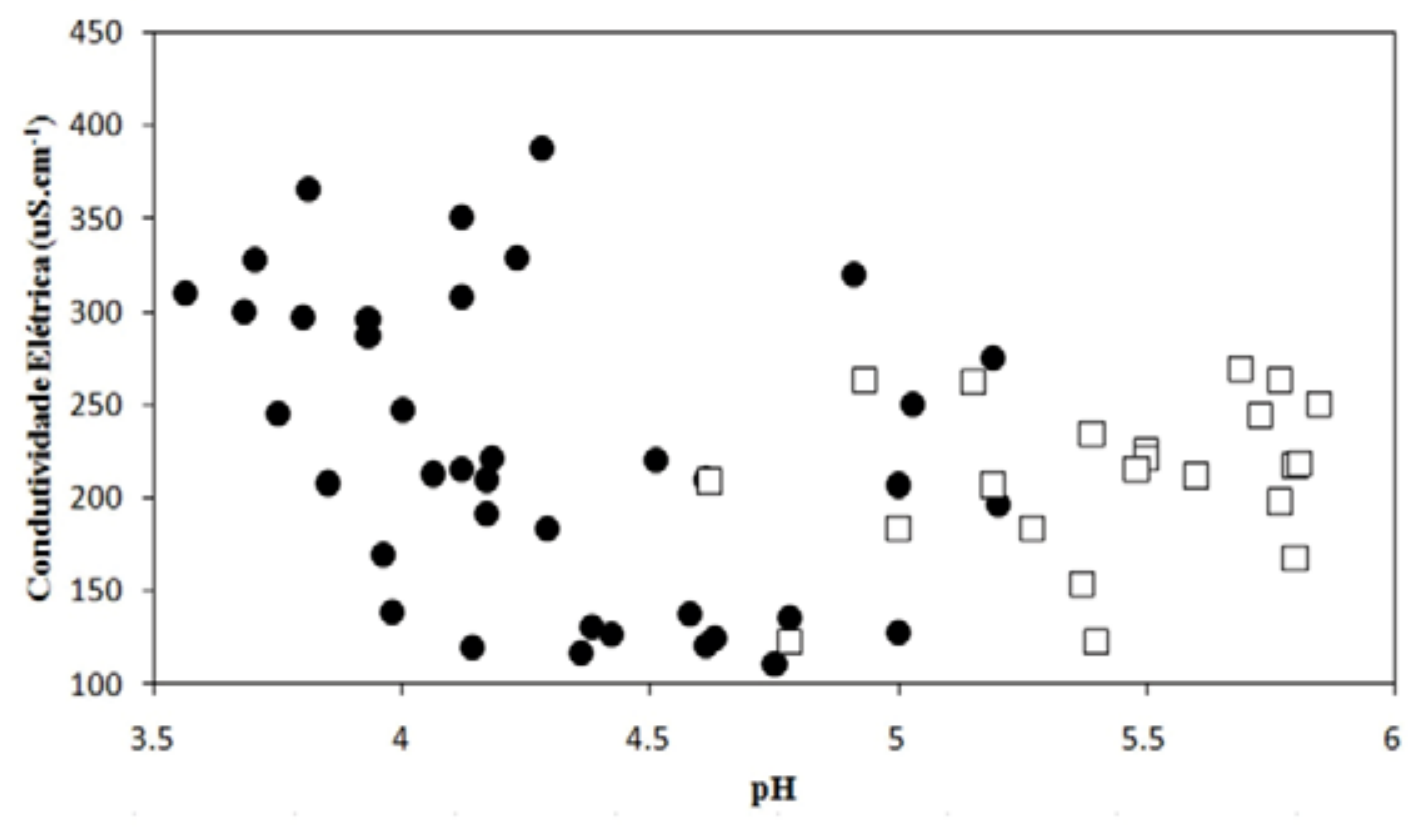

Lagoas

Poços

Figura 4 - Gráfico de dispersão da CE em função do pH das amostras das lagoas e poços. 

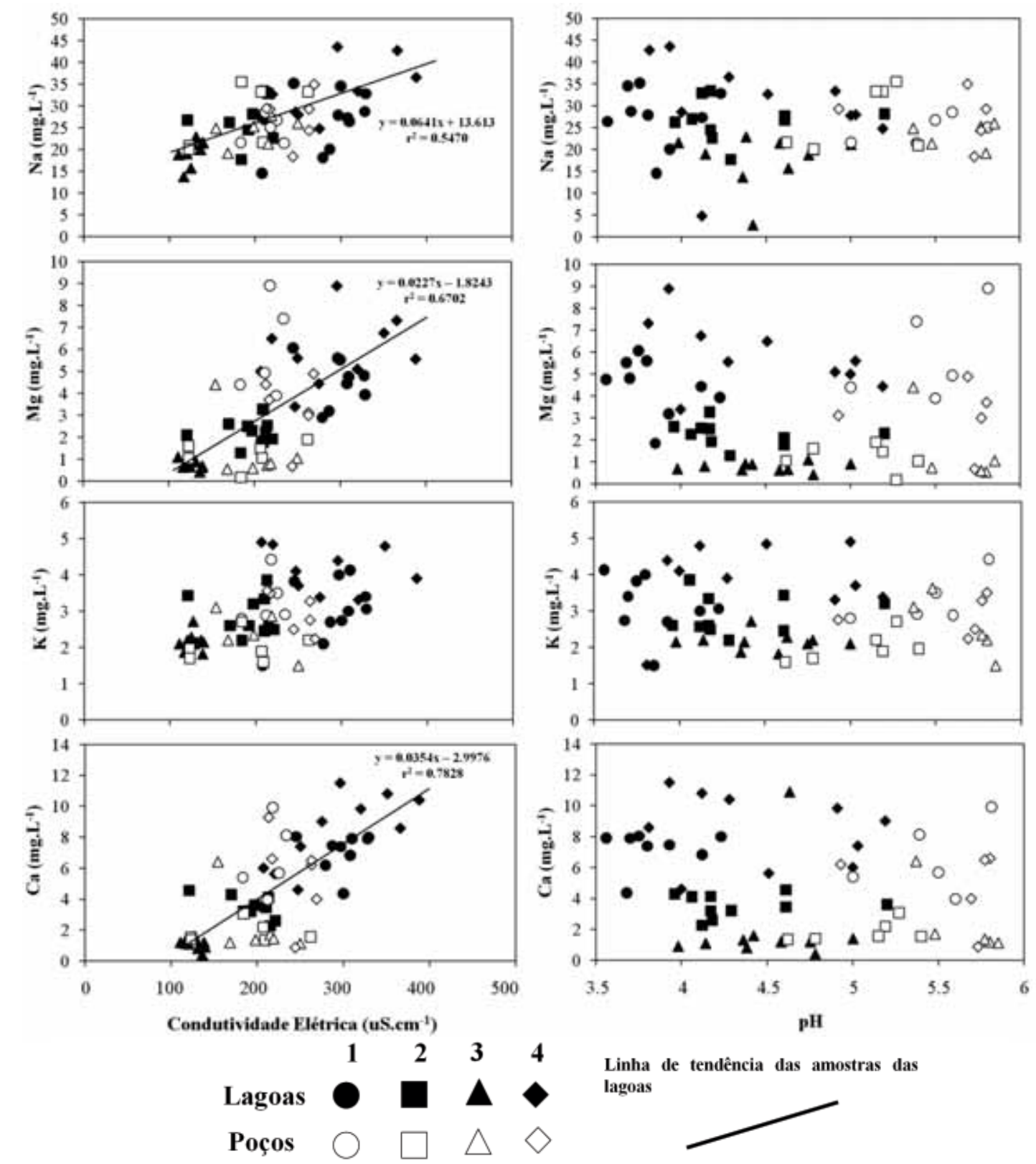

Linha de tendência das amostras das lagoas

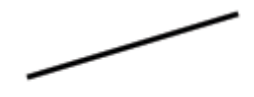

Figura 5 - Concentrações de $\mathrm{Na}, \mathrm{Mg}$, Ca e K em função da CE e pH ao longo do estudo.

apesar de valores ligeiramente mais altos para os poços. Segundo Marques et al. (2008), a sílica nas lagoas encontra-se no estado coloidal devido às faixas de $\mathrm{pH}$, podendo-se afirmar que em faixas de $\mathrm{pH}$ maiores, nos poços, a sílica mantém o mesmo comportamento das lagoas. $\mathrm{O} \mathrm{Al}$ apresenta dois grupos distintos em relação ao $\mathrm{pH}$, num primeiro apresenta valores abaixo de 1 mg. $\mathrm{L}^{-1}$ e no outro acima deste valor, em amostras tanto das lagoas quanto dos poços. Este comportamento pode estar associado, assim como para outros componentes em relação à $\mathrm{CE}$, a fatores externos, os quais fazem com que o comportamento do Al seja variável em relação ao $\mathrm{pH}$ tanto nos poços quanto nas lagoas. O $\mathrm{Cl}$ apresenta a maioria de seus valores de concentração entre 20 e $40 \mathrm{mg} . \mathrm{L}^{-1}$ tanto nas águas das lagoas (mais ácidas) quanto nos poços (menos ácidas), mostrando um comportamento conservativo em relação aos demais íons analisados. $\mathrm{O}$ ânion nitrato, tal qual seu comportamento em relação à $\mathrm{CE}$, não apresenta tendência em relação ao $\mathrm{pH}$, em contrapartida, o bicarbonato, considerando tanto as amostras das lagoas quanto a dos poços, apresenta correlação positiva e significativa com o pH, mostrando uma "transição" dos poços (maior pH) para as lagoas (menor $\mathrm{pH}$ ),

A tabela 2 apresenta a análise por componentes principais (ACP) do conjunto de dados tanto das lagoas quanto das águas subterrâneas, com objetivo de discutir origem e comportamento dos elementos analisados. Esta análise estatística multivariada mostra de forma probabilística quais processos geoquímicos são determinantes das características dessas águas. A ACP, aplicada ao conjunto de dados das lagoas, produz três 

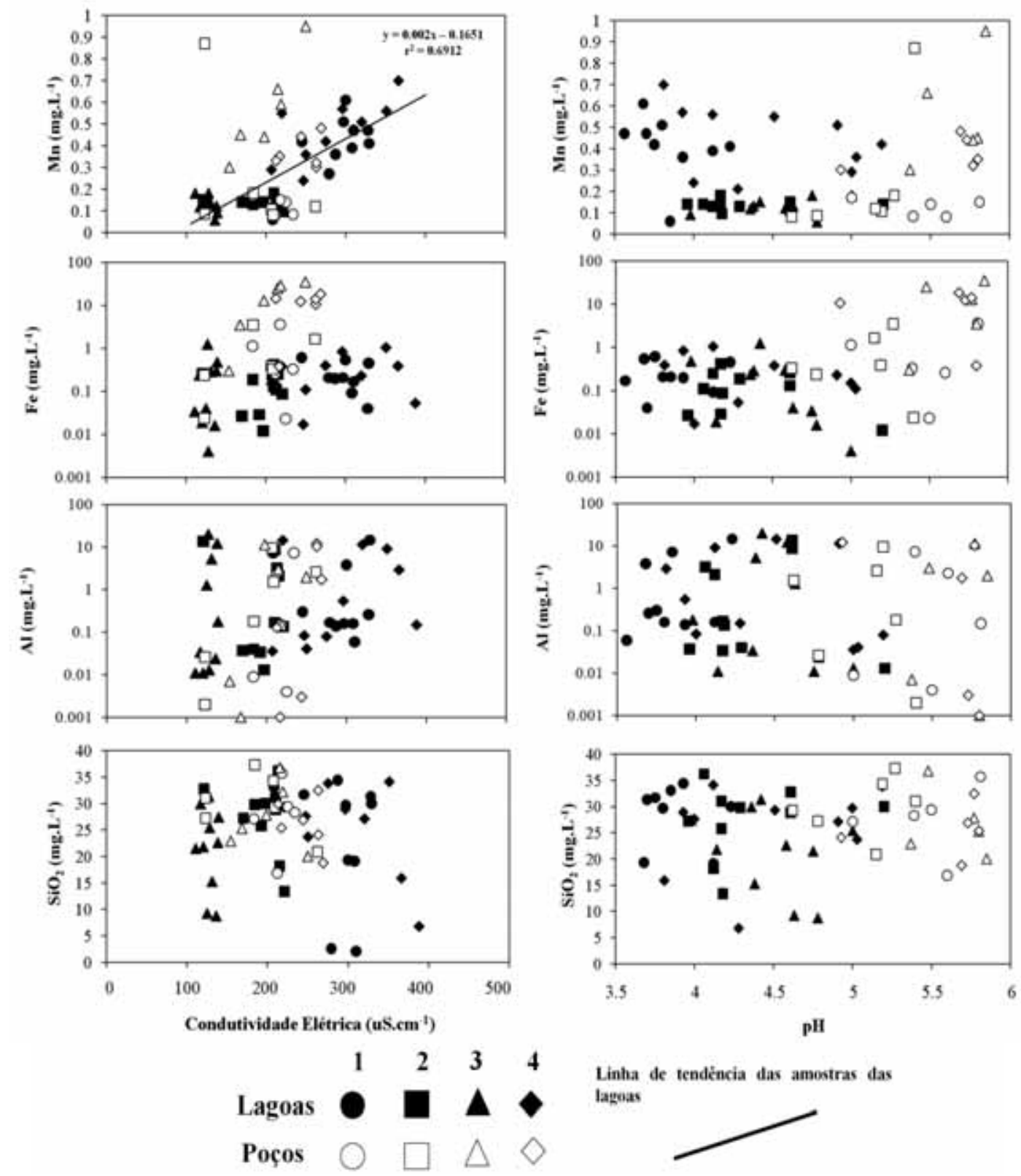

Linha de tendéncia das amostras das lagoas

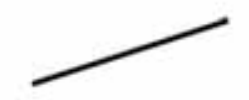

Figura 6 - Concentrações de $\mathrm{Mn}, \mathrm{Fe}$, $\mathrm{Al}$ e $\mathrm{SiO}_{2}$ em função da $\mathrm{CE}$ e pH ao longo do estudo.

fatores que, juntos, explicam $68 \%$ da variância total dos mesmos. O fator 1 , que representa $35 \%$ da variância dos dados, mostra significativos valores de correlação $(>0,50)$ com $\mathrm{Mn}, \mathrm{K}, \mathrm{Ca}, \mathrm{Na}, \mathrm{Mg}, \mathrm{SO}_{4}, \mathrm{Cl}$ e $\mathrm{CE}$, sugerindo que processo de oxidação de camadas redutoras durante a extração de areia produz íons $\mathrm{SO}_{4}$ e acidez, disponibilizando para a coluna d'água $\mathrm{Mn}, \mathrm{Na}, \mathrm{Ca}, \mathrm{Mg}$, e $\mathrm{K}$, antes presentes em sítios de troca, influenciando diretamente no aumento da CE. O fator 2, que explica $17 \%$ da variância total dos dados, apresenta valores de correlação significativos e negativos com o $\mathrm{Fe}, \mathrm{Al}$ e $\mathrm{SiO}_{2}$, sugerindo que a presença de formas coloidais tem papel importante no controle da composição química dessas águas. O terceiro fator explica $16 \%$ da variância e mostra associação negativa e significativa com $\mathrm{pH}$ e bicarbonato, parâmetros diretamente relacionados com o frágil tamponamento (águas extremamente diluídas) das águas das lagoas.

A ACP, aplicada ao conjunto de dados dos poços, mostra 4 fatores que, juntos, explicam $70 \%$ da variância total dos dados. O fator 1 , que explica $26 \%$ da variância dos dados, com valores de correlação significativos para $\mathrm{Mg}, \mathrm{K}, \mathrm{Ca}$ e $\mathrm{SO}_{4}$, e a exemplo das lagoas, indicativo da oxidação de sulfetos de camadas redutoras, produção de acidez e liberação de cátions maiores. $O$ fator 2 , com $21 \%$ da variância dos dados, mostra valores significativos positivos para $\mathrm{pH}, \mathrm{Mn}$ e Fe e negativo para Eh. Este fator sugere que os processos de oxirredução têm papel importante no controle dos elementos-traço. Valores de Eh, quando negativos (ambiente redutor), em condições de maior $\mathrm{pH}$, solubilizam íons Fe e Mn e, quando os valores de Eh se tornam positivos, os íons Fe 

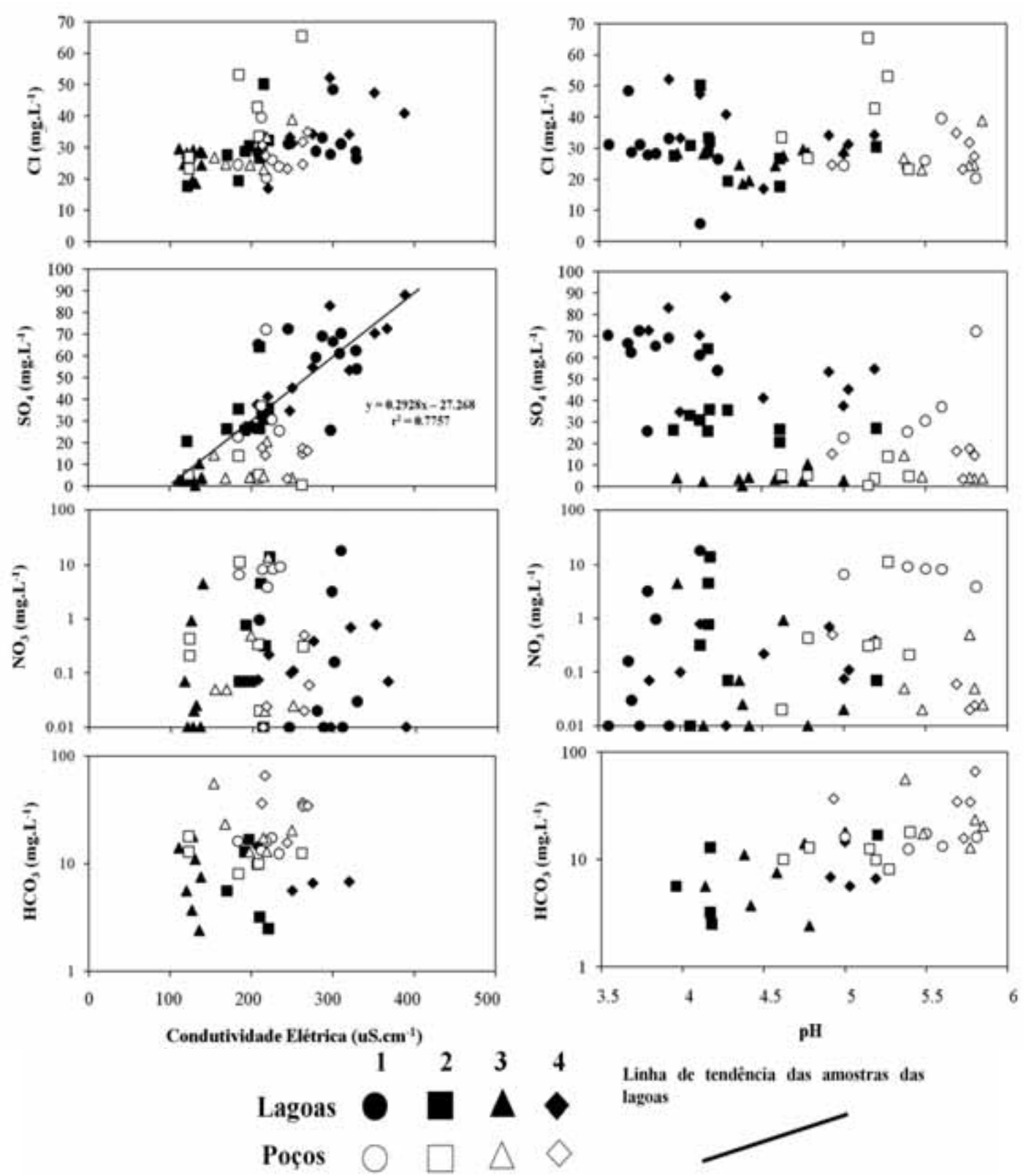

Linha de tendéncia das amostras das lagoas



Figura 7 - Concentrações de $\mathrm{Cl}, \mathrm{SO}_{4}, \mathrm{NO}_{3}$ e $\mathrm{HCO}_{3}$ em função da $\mathrm{CE}$ e pH ao longo do estudo.

e Mn são retirados do meio aquoso através da formação de óxidos-hidróxidos. O fator 3 (14\% da variância dos dados) mostra valores significativos positivos para $\mathrm{Na}$, $\mathrm{Cl}$ e $\mathrm{CE}$, sugerindo que as águas subterrâneas possam ser influenciadas por sais marinhos e/ou por águas de despejo doméstico. $\mathrm{O}$ fator 4 apresenta correlação positiva e significativa com bicarbonato e sílica, sugerindo que o intemperismo dos silicatos é o fator de menor importância ( $10 \%$ da variância) no controle da composição química das águas dos poços.

A partir dos dados extraídos da ACP, é possível fazer observações sobre as fontes dos principais compostos presentes na água. Os íons $\mathrm{Na}, \mathrm{Mg}, \mathrm{K}$ e Ca, além de $\mathrm{Cl}, \mathrm{Mn}$ e $\mathrm{Fe}$, podem ser relacionados às litologias argilosas de características redutoras, de fácies sedimentares flúvio-marinha e flúvio-lacustre. $\mathrm{O} \mathrm{Cl}$ pode, ainda, ser proveniente de aerossóis marinhos, devido à proximidade da costa (a área se situa a menos de $15 \mathrm{~km}$ da baía de Sepetiba). Ainda para $\mathrm{Na}, \mathrm{Mg}, \mathrm{K}$ e Ca, estes podem ter pequena porcentagem de contribuição do intemperismo de minerais silicáticos presentes nas litologias, principalmente de argilominerais e alguns minerais primários, tais como feldspatos e micas (Marques et al. 2008). Dos minerais silicáticos também se origina a $\mathrm{SiO}_{2}$ nas águas, e considerando as faixas de $\mathrm{pH}$ na forma coloidal ácido silícico $\left(\mathrm{H}_{4} \mathrm{SiO}_{4}\right)$. A equação 3 mostra a reação de hidrólise sobre o mineral primário plagioclásio originando caulinita (argilomineral) e ácido silícico.


as e, por vezes, de poços, resultado da atividade de 
Impacto da Mineração de Areia sobre a Química das Águas Subterrâneas, Distrito Areeiro da Piranema, Municípios de Itaguaí e Seropédica, Rio de Janeiro

Tabela 2 - Matriz dos fatores segregados da análise de componentes principais obtidos dos dados das águas das lagoas e dos poços (rotação Varimax normalizado; em negrito itálico, valores significativos $\geq( \pm)$ 0,50).

\begin{tabular}{|c|c|c|c|c|c|c|c|}
\hline Lagoas & & & & ços & & & \\
\hline Fator 1 & Fator 2 & Fator 3 & & Fator 1 & Fator 2 & Fator 3 & Fator 4 \\
\hline$-0,16$ & $-0,14$ & $-0,85$ & pH & 0,30 & 0,75 & 0,02 & $-0,06$ \\
\hline$-0,21$ & 0,24 & 0,05 & Eh & $-0,16$ & $-0,87$ & 0,00 & 0,22 \\
\hline 0,85 & 0,01 & 0,32 & CE & 0,18 & 0,41 & 0,68 & $-0,05$ \\
\hline 0,67 & 0,24 & $-0,16$ & $\mathrm{Na}$ & 0,10 & $-0,02$ & 0,84 & $-0,20$ \\
\hline 0,94 & $-0,13$ & 0,10 & Mg & 0,88 & $-0,18$ & 0,04 & $-0,19$ \\
\hline 0,67 & $-0,30$ & $-0,24$ & $\mathbf{K}$ & 0,87 & 0,26 & $-0,05$ & 0,12 \\
\hline 0,63 & $-0,08$ & 0,35 & $\mathrm{Ca}$ & 0,94 & $-0,02$ & 0,05 & $-0,15$ \\
\hline 0,80 & $-0,20$ & 0,16 & Mn & $-0,40$ & 0,73 & $-0,23$ & $-0,07$ \\
\hline 0,14 & $-0,80$ & 0,29 & $\mathrm{Fe}$ & $-0,23$ & 0,84 & 0,20 & 0,12 \\
\hline 0,50 & 0,13 & 0,21 & Cl & $-0,35$ & $-0,24$ & 0,76 & $-0,08$ \\
\hline 0,85 & 0,02 & 0,39 & $\mathrm{SO}_{4}$ & 0,87 & $-0,07$ & 0,01 & 0,15 \\
\hline$-0,25$ & 0,40 & 0,23 & $\mathrm{NO}_{3}$ & $-0,19$ & 0,29 & $-0,28$ & 0,08 \\
\hline$-0,22$ & 0,21 & $-0,76$ & $\mathrm{HCO}_{3}$ & 0,33 & 0,30 & $-0,11$ & $\begin{array}{l}-0,73 \\
\end{array}$ \\
\hline 0,14 & $-0,54$ & $-0,28$ & $\mathrm{SiO}_{2}$ & 0,19 & 0,05 & $-0,14$ & 0,82 \\
\hline$-0,15$ & $-0,81$ & 0,05 & Al & $-0,01$ & 0,03 & 0,45 & 0,21 \\
\hline 4,75 & 2,11 & 2,06 & $\begin{array}{l}\text { Porcentagem da } \\
\text { Variância }\end{array}$ & 3,84 & 3,08 & 2,16 & 1,47 \\
\hline 35 & 17 & 16 & $(\%)$ & 26 & 21 & 14 & 10 \\
\hline
\end{tabular}

extração de areia, origina íons $\mathrm{H}^{+}$e $\mathrm{SO}_{4}$. O bicarbonato proveniente provavelmente de fácies sedimentares flúvio-marinhas, praticamente desaparece devido aos baixos valores de $\mathrm{pH}$ das águas das lagoas, o que não acontece com as águas dos poços, onde concentrações de bicarbonato atingem valores acima de $60 \mathrm{mg} \cdot \mathrm{L}^{-1}$.

A principal consequência da extração de areia, nesta região, é a acidificação das águas com consequente solubilização do $\mathrm{Al}$, oriundo de minerais primários presentes nos sedimentos, mas principalmente de argilominerais intensamente solubilizados pela atividade de íons $\mathrm{H}^{+}$. Em ambientes aquosos ácidos, o alumínio é tóxico para peixes, anfíbios e fitoplâncton (Driscoll \& Schecher 1969, Birge 1978, Poléo 1995) e é geralmente mais tóxico entre $\mathrm{pH} 4,4$ e 5,4, com toxicidade máxima entre pH 5,0 e 5,2 (Campbell et al. 1983, Klöppel et al. 1990). As espécies monoméricas de $\mathrm{Al}$ mais tóxicas $\left[\mathrm{Al}(\mathrm{OH})^{2+} \mathrm{e} \mathrm{Al}(\mathrm{OH})_{2}^{+}\right]$têm maior reação com a superfície de membranas de organismos aquáticos do que as formas poliméricas e orgânicas (Baird 1998, Camilleri et al. 2003). O alumínio é o sexto metal mais tóxico para esses animais, depois apenas do mercúrio, cobre, zinco, cádmio e estanho (Vuorinen et al. 1990, Exley et al. 1991, Poléo 1995, Poléo et al. 1997).

Por outro lado, a principal preocupação com o Al se deve ao fato de estar associado a doenças neurodegenerativas em seres humanos. Dentre elas, o Mal de Alzheimer, que é caracterizado pela presença de agregados proteicos entre os neurônios que impedem a atividade sináptica resultando na perda de neurônios (Becaria et al. 2002). Muito dos dados que associam a exposição ao $\mathrm{Al}$ e Mal de Alzheimer foram derivados de estudos epidemiológicos de $\mathrm{Al}$ em águas de abastecimento (Martyn \& Pippard 1988, Martyn et al. 1989).

A formação de fases coloidais do alumínio, principalmente nas águas das lagoas, tem relevância do ponto de vista ecológico/ambiental para as lagoas, pois retiram o Al dissolvido da coluna d'água. Pela composição das águas das lagoas, a fase coloidal sulfatada é, provavelmente, a predominante e suas principais formas são a alunita $\left[\mathrm{KAl}_{3}\left(\mathrm{SO}_{4}\right)_{2}(\mathrm{OH})_{6}\right]$ e a jurbanita $\left(\mathrm{AlOHSO}_{4}\right.$ ), como mostrado por Marques et al. (2010), através de modelamento hidrogeoquímico das águas das lagoas. Em contrapartida, as águas dos poços provavelmente apresentam os hidroxialumino-silicatos como as fases predominantes, representadas pelos minerais reativos allofana $[\mathrm{Al}(\mathrm{OH}) 3][(1-\mathrm{x})[\mathrm{SiO} 2] \mathrm{x}] \mathrm{e}$ imogolita $\mathrm{Al}_{2} \mathrm{SiO}_{3}(\mathrm{OH})_{4}$, ambas da mesma família.

Estas fases coloidais podem, ainda, influenciar a cor das águas das lagoas, principalmente as fases sulfatadas, verificadas em lagoas formadas por exploração de minas sulfetadas (minas ácidas). Estas fases coloidais também contribuem para a retirada, através de coagulação, de particulado fino (silte e argila) da coluna d'água (Von Sperling 1988, Fripp et al. 2000, Demas et al. 2004).

Em resumo, a dinâmica de influência dos areais na água subterrânea inicia-se com o processo de 
extração da areia que promove a diminuição do $\mathrm{pH}$, contribuindo para maior dissolução de minerais primários e argilas (aumento da taxa de intemperismo), além de promover a dessorção de alguns componentes presentes em sítios de troca iônica, tais como matéria orgânica e argilominerais, fazendo com que a CE apresente valores mais altos e com maior faixa de valores (entre 111 e $\left.388 \mu \mathrm{S} . \mathrm{cm}^{-1}\right)$. O contrário acontece nos poços, onde o $\mathrm{pH}$ possui valores mais altos, pois não há um processo de oxidação efetivo das camadas em estado redutor, logo, mostra valores de CE menores. Este fato pode ser indicativo de que o íon $\mathrm{SO}_{4}$ seria o principal responsável pelos maiores valores de $\mathrm{CE}$ nas lagoas, já que este íon diminui em concentração na água subterrânea. Nos poços, as concentrações de $\mathrm{HCO}_{3}$ aumentam, porém, os teores dos demais íons são equiparados aos das lagoas, com exceção de $\mathrm{SO}_{4}$ (mais altos nas lagoas). Isto pode se dever à influência da água das cavas sobre a água subterrânea (variações de nível em função da diferença de carga hidráulica), em torno da mesma ou os próprios poços, dependendo se atingem ou não camadas com sedimentos redutores, desencadeiam pontualmente o processo de oxidação deste material, lixiviando tais íons para a água subterrânea.

CONCLUSÕES As lagoas de extração de areia formam um ambiente peculiar devido a sua acidificação, originando uma composição atípica da água comparada com outros corpos d'água naturais, se assemelhando a lagoas de minas sulfetadas. Uma comparação, entre os teores dos componentes das águas subterrâneas da região com as águas das lagoas de extração de areia, indica que o processo da atividade de extração de areia é o fator que desencadeia mudanças na química da água. Apesar desta peculiaridade, as águas das lagoas se mostram com baixo conteúdo de elementos dissolvidos (vide baixos valores de condutividade elétrica), similares às águas subterrâneas.

A dissolução dos alumino-silicatos promove o controle da disponibilidade de alumínio dissolvido na coluna d'água, através da formação de hidroxialumino-silicatos. A oxidação do material geológico reduzido, contendo pirita neoformada e $\mathrm{H}_{2} \mathrm{~S}$, fornece significativas quantidades de $\mathrm{SO}_{4}$, fazendo com que o Al se complexe preferencialmente a este, formando sais complexos. A formação destes sais complexos é responsável pela baixa quantidade de material em suspensão nas lagoas e pela coloração azulada aparente da água.

Apesar de pouco provável, devido a faixa de $\mathrm{pH}$ mais elevada (4,9-5,6; Barbosa 2005), pode-se conjecturar a extensão do alumínio nos fluxos de águas subterrâneas. Poços localizados próximos aos areais podem sofrer variações de nível ou até mesmo terem sido perfurados sobre camadas redutoras, o que poderia desencadear oxidação do material geológico com produção de acidez e liberação de compostos para a água, tais como $\mathrm{Al}, \mathrm{Mn}$ e $\mathrm{Fe}$, contaminando então a água para consumo. Tubbs (1999) já registrou altos teores de Mn em águas de poços locados na região da Piranema.

Agradecimento Este trabalho contou com apoio da FAPERJ - processo E26/171.014/03 e ao INCT-TMCOcean 573-601/2008-9.

\section{Referências}

Alpers C.N. \& Blowes D.W. 1994. Environmental geochemistry of sulphide oxidation. In: ACS, American Chemical Society Symposium, Series 550, Abstracts, p. 13-14.

ANEPAC - Associação Nacional das Entidades de Produtores de Agregados para Construção Civil. 2008. Informações Técnicas. São Paulo, Revista Areia \& Brita 43, 90 p.

Bachmann T.M., Friese K., Zachmann D.W. 2001. Redox and $\mathrm{pH}$ conditions in the water column and in the sediments of an acidic mining lake. Journal of Geochemical Exploration, 73:75-86.

Barbosa C.F. 2005. Hidrogeoquímica e a contaminação por nitrato em água subterrânea no bairro Piranema, Seropédica-RJ. Dissertação de Mestrado, Instituto de Geociências, Universidade Estadual de Campinas, Campinas, $101 \mathrm{p}$.

Baird C. 1998. Environmental Chemistry, 2.ed., Ontario, Bookman, $622 \mathrm{p}$.

Becaria A., Campbell A., Bondy S.C. 2002. Aluminum as a toxicant. Toxicology and Industrial Health, 18:309-320.

Berbert M.C. 2003. A mineração de areia no distrito areeiro de Itaguai-Seropédica/RJ: geologia dos depósitos e caracterização das atividades de lavra e dos impactos ambientais. Dissertação de Mestrado, Instituto de
Geociências, Universidade Federal do Rio de Janeiro, Rio de Janeiro, $132 \mathrm{p}$.

Bidone E.D., Silva-Filho E.V., Guerra T., Barroso L.V., Ovalle A.R.C. 1999. Natural and cultural nutrient levels in rivers of small coastal watersheds, S-SE, Brazil. In: Knoppers B., Bidone E.D., Abrão J.J. (eds.) Environmental Geochemistry of Coastal Lagoon Systems of Rio de Janeiro, Brazil. Niterói, EDUFF, p. 120-132.

Birge W.J. 1978. Aquatic Toxicology of trace elements of coal and fly ash. In: Thorp J.H., Gibbons J.W. (eds.) Energy and Environmental Stress in Aquatic Systems, Augusta, GA. Washington, Springfield, p. 219-240.

Camilleri C., Markich S.J., Noller B.N., Turley C.J., Parker G., Van Dan R.A. 2003. Silica reduces the toxity of aluminium to a tropical freshwater fish (Mogurnda mogurnda). Chemosphere, 50:355-364.

Campbell P.G.C., Bisson M., Bougie R., Tessier A., Villeneuve J. 1983. Analytical methodology for determining the speciation of aluminum in acidic freshwaters. Analytical Chemistry, 55:2246-2252.

Cunha F.G. \& Machado G.J. 2003. Manual Simplificado Sobre os Procedimentos de Coleta de Água Superficial $e$ de Consumo Doméstico. Belo Horizonte, CPRM, Manual Técnico, $58 \mathrm{p}$. 
Custodio E. \& Llamas M.R. 1983. Hidrologia subterrânea. Madrid, Omega, 603 p.

Demas S.Y., Hall A.M., Fanning D.S., Rabenhorst M.C., Dzantor E.K. 2004. Acid sulfate soils in dredged materials from tidal Pocomoke Sound in Somerset County, MD, USA. In: International Acid Sulfate Soils Conference, 5, Tweed Heads, Twin Towns Services Club, Abstracts, p. 8.

Denimal S., Bertrand C., Mudry J., Paquette Y., Hochart M., Steinmann M. 2005. Evolution of the aqueous geochemistry of mine pit lakes e Blanzy-MontceaulesMines coal basin (Massif Central, France): origin of sulfate contents, effects of stratification on water quality. Applied Geochemistry, 20:825-839.

DNPM - Departamento Nacional de Produção Mineral. 2006. Anuário Mineral Brasileiro. Brasília, DNPM, Anuário 34, $777 \mathrm{p}$.

Driscoll C.T. \& Schecher W.D. 1969. Aqueous Chemistry of Aluminium. In: Gitelman H.J. Aluminium and Health, A Critical Review. New York, Springer-Verlag, p. 209-225.

Eletrobolt 2003. Estudos Hidrogeológicos dos Aqüiferos Intergranulares a Oeste do Rio Guandu, Município de Seropédica/RJ. Seropédica, Sociedade Fluminense de Energia Ltda., Relatório de Consultoria Técnica, 234 p.

Exley C., Chappell J.S., Birchall J.D. 1991. A mechanism for acute aluminium toxicity in fish. Journal of Teorical Biology, 151:517-428.

Fripp J., Ziemkiewicz P.F., Charkavorki H. 2000. Acid mine drainage treatment, Vicksburg, MS. Vicksburg, U.S. Army Engineer Research and Development Center, Technical Notes Collection - ERDC TN-EMRRPSR-14, $310 \mathrm{p}$.

Góes M.H.B. 1994. Sobre a Formação Piranema da Bacia do Rio Guandu (RJ): um estudo paleoambiental. In: Congresso Brasileiro de Geologia, 38, Anais, p. 322-323.

Góes M.H.B. 1999. Diagnóstico Ambiental por Geoprocessamento do Município de Itaguaí, RJ. Tese de Doutorado, Instituto de Geociências, Universidade Estadual Paulista Júlio de Mesquita Filho, Rio Claro, $204 \mathrm{p}$.

Jambor J.L. \& Blowes D. 1994. Environmental geochemistry of sulfidic mine wastes, Nepean. Ontario, Mineral Association of Canada, $438 \mathrm{p}$.

Klöppel H., Kordel W., Schmid S., Klein W. 1990. Development and improvement of analytical methods for speciation scheme of $\mathrm{Al}$ in the mobile soil phase. In: Broekaert J.A.C., Gilcer S., Adams F. (eds.) Proceedings ASI Metal speciation in the environment. Berlin, Springer-Verlag, p. 447-461.

Lopes I., Gonçalves F., Soares A.M.V.M., Ribeiro R. 1999. Discriminating the ecotoxicity due to metals and to low $\mathrm{pH}$ in acid mine drainage. Ecotoxicology and Environmental Safety, 44(2):207-214.

McCullough C.D. \& Lund M.A. 2006. Opportunities for sustainable mining pit lakes in Australia. Mine Water Environ, 25:220-226.

Marques E.D. 2010. Impacto da mineração de areia na bacia sedimentar de Sepetiba, RJ: estudo de suas implicações sobre as águas do Aqüifero Piranema. Tese de Doutorado Departamento de Geoquímica, Universidade Federal Fluminense, Niterói, $161 \mathrm{p}$.
Marques E.D., Sella S.M., de Mello W.Z., Lacerda L.D., Silva-Filho E.V. 2008. Hydrogeochemistry of Sand Pit Lakes at Sepetiba Basin, Rio de Janeiro, Southeastern Brazil. Water, Air and Soil Pollution, 189:21-36.

Marques E.D., Sella S.M., Bidone E.D., Silva-Filho E.V. (2010) Geochemical behavior and dissolved species control in acid sand pit lakes, Sepetiba sedimentary basin, Rio de Janeiro, SE Brazil. Journal of South American Earth Sciences, 30:176-188.

Martyn C.N. \& Pippard E.C. 1988. Aluminum and Alzheimer's disease: an epidemiological approach. $J$ Epidemiol Community Health, 42:134-137.

Martyn C.N., Baker D.J.P., Osmond C., Harris E.C., Edwardson J.A., Lacey R.F. 1989. Geographical relation between Alzheimer's disease and aluminum in drinking water. Lancet, 1:59-60.

Modis K., Adam K., Panagopoulos K., Komtopoulos A. 1998. Development and Validation of a geostatistical model for prediction of acid mine drainage in underground sulphide mines. Transaction of the Institution of Mining and Metallurgy, 107:102-107.

Neil L.L., McCullough C.D., Lund M.A., Evans L.H., Tsvetnenko Y. 2009. Toxicity of acid mine pit lake water remediated with limestone and phosphorus. Ecotoxicology and Environmental Safety, 72(8):2046-2057.

Nimer E. 1977. Descrição, Análise e Interpretação Conceitual do Sistema de Classificação de Climas de C, W, Thornthwaite. Revista Brasileira de Geografia, 1:87-109.

Pellicori D.A., Gammons C.H., Poulson S.R. 2005. Geochemistry and stable isotope composition of the Berkeley pit lake and surrounding mine waters, Butte, Montana. Applied Geochemistry, 20(11): 2116-2137.

Plumlee G.S. \& Logsdon M.J. 1999. The environmental geochemistry of mineral deposits. Rev Econ Geol, 6:224-240.

Poléo A.B.S. 1995. Aluminium polymerisation - a mechanism of acute toxicity of aqueous aluminium to fish. Aquatic Toxicol, 31(4):347-356.

Poléo A.B.S., Ostrabye K., Osnevad S.A., Andersen R.A., Heibo E., Vollestad L.A. 1997. Toxicity of acid aluminium-rich water to seven freshwater fish species: a comparative laboratory study. Environmental Pollution, 96(2):129-139.

Ramstedt M., Carlsson E., Lövgren L. 2003. The aqueous geochemistry in the Udden pit lake, northern Sweden. Applied Geochemistry, 18:97-108.

Rios J.L.P. \& Berger S.G. 2002. Estudos sócio-econômicos e de demanda de água para a RMRJ. In: SERLA, Seminário sobre a bacia hidrográfica do Rio Guandu: problemas e soluções, 1, Anais, p. 30-34.

Schultze M., Pokrandt K., Hille W. 2010. Pit lakes of the Central German lignite mining district: Creation, morphometry and water quality aspects. Limnologica - Ecology and Management of Inland Waters, 40(2):148-155.

SEMA - Secretaria de Estado do Meio-ambiente. 1996. Projeto I: Diagnóstico ambiental da Bacia Hidrográfica da Baía de Sepetiba: Programa de Zoneamento Econômico-Ecológico do Estado do Rio de Janeiro - ZEE/RJ. Rio de Janeiro, CARTOGEO/NCE/UFRJ, Relatório Técnico, 63 p. 
Sheoran A.S. \& Sheoran V. 2006. Heavy metal removal mechanism of acid mine drainage in wetlands: a critical review. Minerals Engineering, 19(2):105-116.

Terrabyte 2000. Mineração Aguapei - Estudo de Impacto Ambiental - EIA. Rio de Janeiro, SEMARH, Relatório Técnico - Tomo B2, $135 \mathrm{p}$.

Tubbs D. 1999. Ocorrência das Águas Subterrâneas e “Aquífero Piranema” e Município de Seropédica, área da Universidade Rural e Arredores, Estado do Rio de Janeiro. Rio de Janeiro, FAPERJ, Relatório Final de Pesquisa, $123 \mathrm{p}$.

Von Sperling E. 1988. Qualidade da Água em Atividades de Mineração.In: Dias L.E., Mello J.W.V.(eds.) Recuperação de Áreas Degradadas. Viçosa, Universidade Federal de Viçosa, p. 1- 251.

Vuorinen P.J., Keinanen M., Peuranen S. 1990. Long term exposure of adult Whitefish (Coregonus wartmanni) to low $\mathrm{pH}$ /Aluminium: effects on reproduction, growth, blood composition and gills. In: Kauppi P., Antilla P., Kenttamies K. (eds.) Acidification in Finland, Berlin, Springer-Verlag, p. 941-961.

Manuscrito ID 18659

Submetido em 21 de setembro de 2010 Aceito em 13 de outubro de 2011 